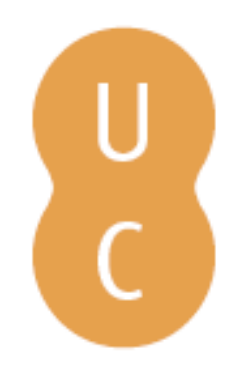

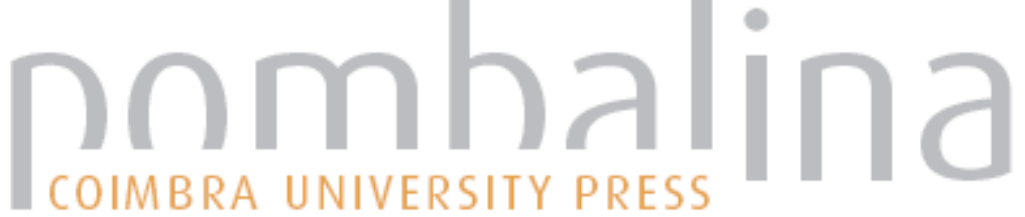

\section{A narrativa como superação da crise}

\author{
Autor(es): $\quad$ Peixinho, Ana Teresa
}

Publicado por: Imprensa da Universidade de Coimbra

URL

persistente: URI:http://hdl.handle.net/10316.2/30734

DOI: $\quad$ DOI:http://dx.doi.org/10.14195/978-989-26-0574-6_10

Accessed : $\quad$ 10-Feb-2016 22:27:13

A navegação consulta e descarregamento dos títulos inseridos nas Bibliotecas Digitais UC Digitalis, UC Pombalina e UC Impactum, pressupõem a aceitação plena e sem reservas dos Termos e Condições de Uso destas Bibliotecas Digitais, disponíveis em https://digitalis.uc.pt/pt-pt/termos.

Conforme exposto nos referidos Termos e Condições de Uso, o descarregamento de títulos de acesso restrito requer uma licença válida de autorização devendo o utilizador aceder ao(s) documento(s) a partir de um endereço de IP da instituição detentora da supramencionada licença.

Ao utilizador é apenas permitido o descarregamento para uso pessoal, pelo que o emprego do(s) título(s) descarregado(s) para outro fim, designadamente comercial, carece de autorização do respetivo autor ou editor da obra.

Na medida em que todas as obras da UC Digitalis se encontram protegidas pelo Código do Direito de Autor e Direitos Conexos e demais legislação aplicável, toda a cópia, parcial ou total, deste documento, nos casos em que é legalmente admitida, deverá conter ou fazer-se acompanhar por este aviso.

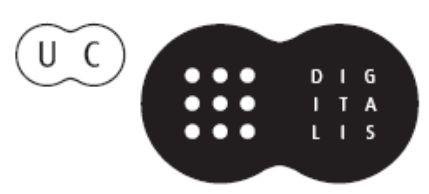




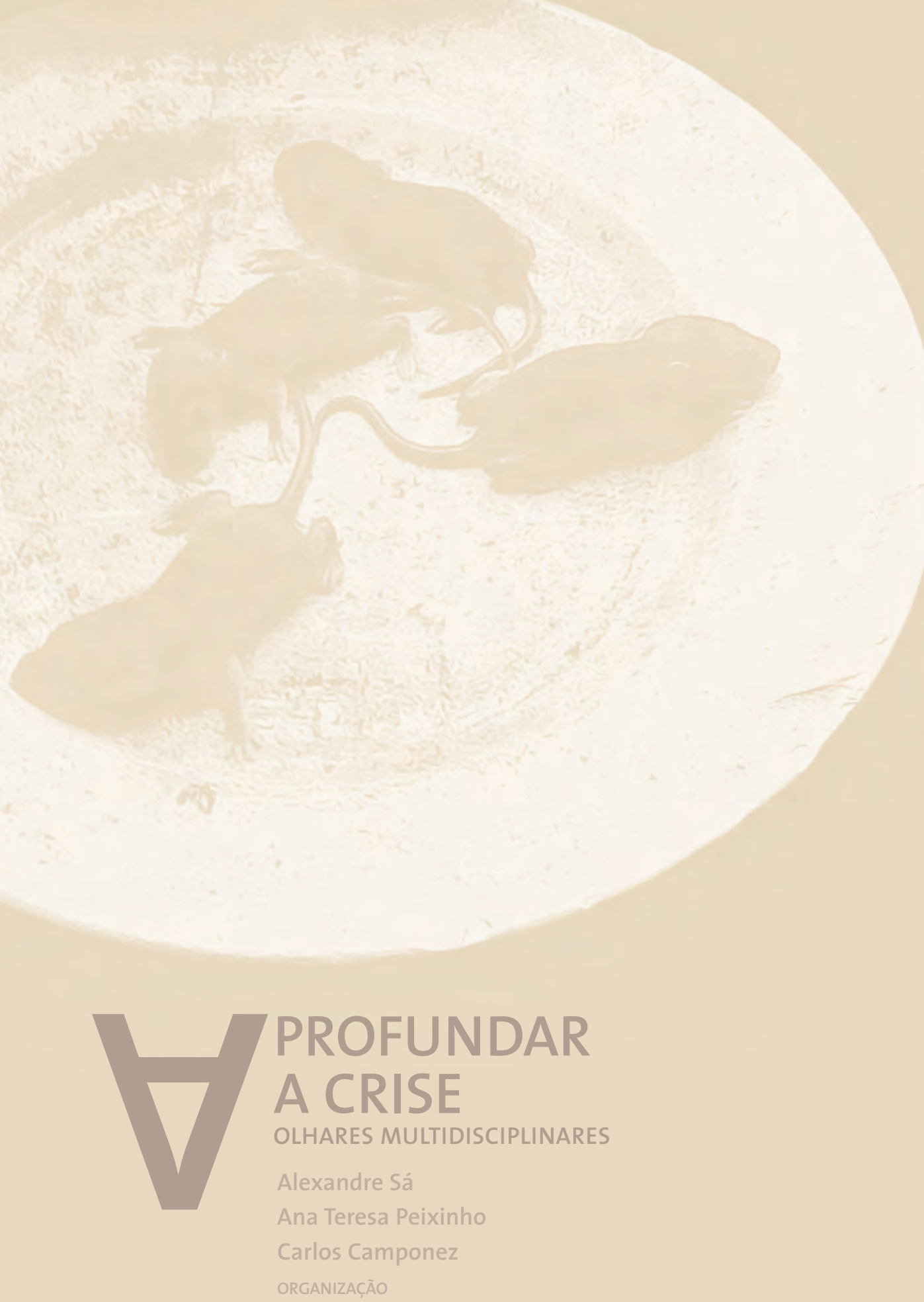


Ana Teresa Peixinho

FLUC - CEIS20

\section{A narrativa como Superação da CRise}

\section{Considerações prévias: a crise dos jornais de papel}

O que pretendo partilhar nesta reflexão prende-se essencialmente com um pressuposto: o de que o Jornalismo vive uma crise sem precedentes, mote que, aliás, tem sido retomado de forma insistente na última década.

O Jornalismo, enquanto atividade e área sociocultural, também não escapa, portanto, à abrangência da crise nas sociedades atuais, sendo ele um campo marcado por problemas endógenos mas também e, seguramente, por tensões externas que dilaceram o campo socioprofissional. Crise de legitimidade profissional, dramática para os jornalistas que têm de encarar despedimentos ou submissões diversas, muitas vezes violentando a sua independência e liberdade; crise de leitura, pois cada vez menos os jornais impressos são comprados e lidos; crise ético-deontológica, assistindo-se a subversões nos critérios de seleção e tratamento das notícias; crise de estratégias e práticas editoriais: estas são algumas das consequências, na nossa opinião, decorrentes da lógica de mercado selvagem que impera sobre o jornalismo, a que Carlos Camponez chama de "crise sistémica das lógicas do novo capitalismo" (Camponez, 2010), e também das mudanças rápidas provocadas pelo surgimento dos novos media que arrastam consigo novos paradigmas de construção do sentido, de escrita e de leitura, tema desenvolvido na conferência do Professor António Fidalgo publicada neste volume.

Na sua lição para Provas de Agregação, Manuel Pinto faz uma radiografia bastante bem circunstanciada das múltiplas crises que atravessam o campo jornalístico na atualidade, explicando como a formação de grandes oligopólios mediáticos e a ditadura da rentabilização que preside à lógica de mercado tiveram 
consequências a dois níveis: por um lado, o desinvestimento nas redações, de onde foram afastados os jornalistas mais experientes, por outro, a aposta numa informação capaz de seduzir o público, mas que passou necessariamente pela tabloidização (Pinto, 2008: 10-11). Neste sentido, chamamos à colação o conceito de hiperconcorrência, proposto pelos investigadores canadianos Jean Charron e Jean Bonville, segundo o qual o centro gravitacional dos media, no tempo presente, é a disputa pela conquista de públicos, através de procedimentos de sedução, muito mais próximos de lógicas de entretenimento hollywoodescas do que de estratégias estruturantes da informação. A necessidade febril de conquistar leitores e espectadores conduziu o jornalismo a um caminho, certamente mais fácil, de optar por um conjunto de estratégias, também nada inovadoras, mas que se vislumbram como receitas propícias a captar a empatia dos públicos: aquilo a que, no fundo, Mário Mesquita chamou já há alguns anos de jornalismo hiperbólico (Mesquita, 2003).

Quando digo que nada disto é inteiramente novo, refiro-me a um aspeto que considero historicamente relevante: a partir do momento em que o jornalismo, neste caso, a imprensa se industrializa adquirindo contornos e matizes semelhantes aos que tem hoje, ela vive esse dilema. Sensacionalismo, excessiva exploração da proximidade, espectacularização: marcas da yellow press, que, no final do século xix, serão responsáveis por uma cisão no campo jornalístico, que, inclusivamente, se refletirá no questionamento da sua legitimidade pública.

Se atentarmos na ampla e acesa discussão que envolveu os intelectuais franceses no fim do século, perceberemos que, a partir do momento em que se massifica, o jornalismo vive este dilema. Entre 1897 e 1898, a Revue Bleue desenvolveu um largo debate sobre o papel da Imprensa, em que se destacaram duas conceções antagónicas de jornalismo: uma de matriz pedagógica que entendia o jornalismo como uma prática com deveres públicos e edificantes, capaz de traduzir ideias e defender princípios, por um lado; por outro, uma conceção mais moderna e consentânea com as inovações importadas do jornalismo americano, que colocava a ênfase na vertente lúdica dos conteúdos do jornal. No fundo, este debate traduzia a tensão sentida no universo jornalístico francês do final do século, como o expressa eloquentemente Ferenczi: 
"os primeiros têm a nostalgia de um jornalismo que pusesse em primeiro plano a literatura, as ideias, a política, que não estivesse sujeito às procupações do dinheiro e que não procurasse multiplicar as reportagens no terreno. Os segundos desejam uma imprensa que tivesse como missão descrever a realidade (...) oferecendo ao público informações exatas, precisas, seguras." (Ferenczi, 1993: 235) $)^{113}$.

Quer isto dizer, portanto, que face às vincadas mudanças no universo da imprensa, decorrentes da propagação das práticas americanas, intelectuais e jornalistas franceses, formados numa arreigada tradição histórica segundo a qual literatura, política e jornalismo se harmonizavam, recusam ceder aos constrangimentos da massificação da imprensa ${ }^{114}$. Ainda no decurso do debate acima referido, aliás lançado pelo filósofo Alfred Fouillée, o senador francês Bérenger, homem de letras e jornalista, abriu a discussão, isolando os dois grandes vícios desta nova imprensa: o excessivo gosto pelo espetacular e sensacional e a corrupção pelo dinheiro (Delporte, 1995: 30-31), afinal, dois dos aspetos que mais críticas suscitaram dos intelectuais oitocentistas e que atualmente têm sido retomados como mote por todos quantos veem de fora o jornalismo ${ }^{115}$.

\section{Em busca da narrativa perdida}

Pretendemos, nesta nossa breve abordagem, perceber o conceito de crise de leitura que afeta os jornais impressos nacionais, defendendo a tese - que, confessamos, não é totalmente original - de que o jornalismo pode encontrar

\footnotetext{
113 Tradução nossa.

114 Num artigo em que analisa a obra Le Sieur de Va-Partout, da autoria de Pierre Giffard, Myriam Boucharenc sintetiza bem esta oposição entre os defensores do velho jornalismo e aqueles que aderiram ao novo jornalismo anglo-americano: "Na aurora da sua modernidade, o jornalismo ainda é largamente um depositário da herança do Segundo Império. (...) a imprensa francesa permanece dominada pelos "velhos marechais da crónica" e só timidamente segue o exemplo dos Stanleys ultramarinos. O confronto é então vivo, e bem conhecido, entre os seguidores do «velho sistema", que lamentam a intrusão da reportagem no muito literário jornal francês (...) e aqueles que se passaram a chamar "Os novos jornalistas", entre os quais Fernand Xau, fundador do Journal, Hugues Leroux, escritor e repórter prolixo, ou ainda Jules Huret, todos advogando um jornalismo de investigação que agradasse ao público." (Boucharenc, 2004: 512). Tradução nossa.

115 Os textos de Carlos Camponez e de João Figueira, publicados neste volume, abordam de forma circunstanciada o panorama da crise do Jornalismo.
} 
um último reduto, caso decida fazer um exercício retrospetivo, recuperando algumas das características que tinha nas suas origens. Sem querermos enveredar por caminhos reacionários ou passadistas, e tendo a perfeita noção da distância de tempos e de contextos, julgamos que o importante papel que a imprensa teve ao longo do século xix pode ser parcialmente recuperado, o que passará, naturalmente, não só por uma revisão do papel dos jornais, mas também por uma abertura destes a novos agentes, implicando uma revisão do papel da escrita e da narrativa na construção dos acontecimentos.

Num artigo recente, precisamente dedicado aos media europeus face à crise, Nobre Correia afirma que se assiste hoje a uma redefinição da função social da imprensa e a uma profunda mutação das práticas jornalísticas. Segundo este estudioso, os jornais em papel recuperarão as funções que inicialmente tiveram ao longo do século xix e nos princípios do século xx, publicando grandes reportagens, análises aprofundadas, opinião e comentários, relegando para o jornalismo digital a função meramente informativa (Correia, 2010: 313).

Este prognóstico, embora não seja propriamente novo nem original, tem sido objeto de discussão por parte de alguns autores e de alguns, poucos, jornalistas. A nós, para a reflexão que aqui partilhamos, interessa-nos retomar este tópico, sobretudo porque julgamos que este novo paradigma do jornalismo escrito, um paradigma "a haver", passa necessariamente por uma profunda reflexão acerca das potencialidades da narrativa como modo fundacional do discurso mediático.

Na década de 60 do século passado, um grupo de grandes repórteres norte-americanos, face àquilo que consideravam ser um divórcio dos leitores em relação ao jornalismo, decidiu revolucionar os modos de reportar, acabando por ter ficado na história como o movimento do New Journalism, tão polémico e problemático. Exemplos célebres como Tom Wolfe, Gay Talese, Truman Capote, Norman Mailer, Tomas B. Morgan, Brock Brower, todos grandes jornalistas de publicações de referência americanas, dotados de excecionais capacidades de escrita, começaram a fugir à escrita padronizada do jornalismo, criando verdadeiras peças narrativas que rapidamente ombrearam os grandes romances da Literatura, quer pela sua qualidade estilística, quer pela densidade das suas tramas: reportagens e artigos que fugiam aos padrões da imparcialidade, isenção, objetividade e cinzentismo da linguagem jornalística, aproximando-se muito da escrita literária. 
Antes, porém, de olharmos para as consequências deste tipo de abordagem jornalística, convém que a entendamos, até porque a questão renasceu na primeira década do século xxi. Para isso, parece-nos crucial reler o "texto-programa" deste movimento, escrito na década de 70 por Tom Wolfe ${ }^{116}$. Na segunda parte, a central do ensaio, o autor explica o que era este movimento, bem como algumas das suas características, começando por exprimir que aquilo que mais o fascinou foi, não apenas o facto de perceber que se conseguia escrever artigos fiéis à realidade empregando técnicas literárias, típicas do conto ou do romance, mas sobretudo descobrir que se podia recorrer a qualquer artifício literário para provocar o leitor de um modo simultaneamente "intelectual e emotivo". No fundo, tratava-se de uma alteração da atitude do jornalista face ao acontecimento: se, no jornalismo tradicional, o repórter se esforçava por ser uma "testemunha objetiva", distanciando-se o mais possível, no ato da escrita; no novo jornalismo, não só a intromissão do "eu" é permitida, mas a presença do jornalista no acontecimento torna-se o fio condutor da narração, garante da economia narrativa.

Wolfe exemplifica, com artigos seus, os procedimentos que começou a adotar e que se assumem como as principais diretrizes desta nova forma de fazer jornalismo: 1) a vOz do narrador deve ceder espaço à vOz das personagens, devendo ser uma voz comprometida e não a voz cinzenta e neutral que era comum nos artigos jornalísticos ${ }^{117}$; 2) a apologia das mudanças de perspetiva e de ponto de vista, utilizando habilmente os códigos narrativos apropriados para esse fim ${ }^{118}$; 3) a forma de recolha do material também era diferente e muito mais ambiciosa, postulando uma maior proximidade entre fontes e repórteres. Jornalistas como Capote $^{119}$ ou Talese fomentaram o hábito de passar dias inteiros com as pessoas

116 No seu ensaio O Novo Jornalismo, o autor explica o contexto sociocultural da emergência desta nova escrita, a sua ligação a técnicas romanescas mais antigas, nomeadamente às do romance realista, o estado de letargia dos romancistas norte-americanos daquela época e a saturação do leitor perante um certo tipo de jornalismo. Trata-se de um texto incontornável para entender a fundo a revolução desencadeada por estes jornalistas-escritores (Wolfe, 1990).

117 "Gostei da ideia de conseguir um artigo que fizesse com que o leitor, através do narrador, falasse com as suas personagens, se entusiasmasse com elas, se identificasse." (Wolfe, 1990: 29).

118 "Em vez de me apresentar como o locutor radiofónico que descreve a grande parada, deslizava o mais rapidamente para o olhar das personagens do artigo. Com frequência, mudava o ponto de vista a meio de um parágrafo ou até de uma frase." (Wolfe, 1990: 31).

11 De facto, no seu trabalho A sangue frio, Capote entrevistou centenas de pessoas próximas da família Clutter e dos assassinos, acumulando documentos suficientes para encher um pequeno quarto. Passou seis anos da sua vida em pesquisa para a história, criando inúmeros amigos na pequena vila de Holcomb, no Texas. 
sobre as quais escreviam, a fim de captar detalhes como expressões faciais, diálogos, gestos, ambientes. Quer isto dizer que a revolução provocada por estes escritores-jornalistas passou não apenas por drásticas alterações na metodologia de pesquisa, requerendo uma imersão do jornalista nas situações, mas também um amplo aproveitamento de signos narrativos, até aí preteridos pelo registo neutral da imprensa.

$\mathrm{Na}$ terceira parte do ensaio, Wolfe enumera outros quatro procedimentos narrativos que fazem parte desta nova técnica ou arte de reportar o real: a construção cena a cena, evitando a narração histórica; o registo do diálogo na sua totalidade, desnudando a personagem ao leitor na sua totalidade, com maior eficácia e rapidez; o recurso à focalização interna; e, finalmente, a exploração do detalhe, conseguido pela valorização da descrição de gestos, sons, cheiros, comportamentos, poses e estilos.

No fundo, aquilo que estes novos jornalistas fazem, segundo Tom Wolfe, é seguir as técnicas do Realismo, particularmente do Realismo oitocentista à Balzac ou à Dickens, começando instintivamente a descobrir os procedimentos que conferiam ao romance realista a sua força única: a capacidade para apaixonar, absorver, através de uma comunicação emotiva fundada na realidade concreta. Ou seja, a imersão exigida ao repórter era a condição sine qua non para a promoção da imersão do leitor, através da criação de um relato que o envolvesse, provocando, no fundo, aquilo que em termos literários podemos chamar de estranhamento ${ }^{120}$.

Esta brevíssima descrição dos procedimentos dos novos jornalistas norte-americanos permite perceber o alcance da polémica que envolveu a receção dos seus trabalhos, quer por parte de jornalistas e jornais mais conservadores, quer por parte de críticos literários ou homens de letras. O epíteto de "parajornalismo" ou "jornalismo bastardo" foi veiculado por conceituados jornais

120 Neologismo proposto pelo formalista russo Viktor Chklovski em "A arte como processo", ensaio publicado na segunda edição da Poetika em 1917. "Para Chklovski, o contrário é que é válido: "A finalidade da arte é dar uma sensação do objeto como visão e não como reconhecimento; o processo da arte é o processo de singularização [ostraniene] dos objetos e o processo que consiste em obscurecer a forma, em aumentar a dificuldade e a duração da perceção. O ato de perceção em arte é um fim em si e deve ser prolongado; a arte é um meio de sentir o devir do objeto, aquilo que já se 'tornou' não interessa à arte." O estranhamento seria então esse efeito especial criado pela obra de arte literária para nos distanciar (ou estranhar) em relação ao modo comum como apreendemos o mundo, o que nos permitiria entrar numa dimensão nova, só visível pelo olhar estético ou artístico." (Ceia, 2011). 
como The New York Review of Books e Columbia Journalism Review. De facto, a variedade e veemência das críticas provocadas pelas reportagens, peças e perfis destes jornalistas, desde meados da década de 60, é por si um sintoma do seu impacto. Vários críticos concluíram que este Novo Jornalismo era perigoso por diversos motivos: arriscava tornar as notícias em mero entretenimento; os diálogos e as cenas poderiam distorcer os factos; as fronteiras entre ficção e factualidade poderiam matizar-se.

No fundo, aquilo que era criticado a este movimento prendia-se com uma questão crucial e muito sensível no jornalismo moderno: a da objetividade. A vertiginosa aproximação destas reportagens à literatura fazia perigar os conceitos de realidade e de factualidade, prementes no jornalismo. Se lermos uma declaração de Truman Capote, em entrevista à New York Book Review em 1966, ano do lançamento do seu sucesso editorial In Cold Blood, conseguiremos captar melhor o que está aqui em causa:

"Parecia-me a mim que jornalismo, reportagem poderiam esforçar-se por atingir uma nova forma de arte séria: a nonfiction novel como eu a imaginei. Muitos admiráveis repórteres (...) mostraram as possibilidades da narrativa de reportagem (...) No seu conjunto, ainda, o jornalismo é o mais subestimado, o menos explorado dos media literários." (Capote, entrevista a New York Book Review, 1966).

Estamos perante um paradigma radicalmente diferente de fazer jornalismo, totalmente distanciado da construção narrativa formatada pelo modelo industrial. O próprio conceito de nonfiction novel é na essência problemático: onde termina a factualidade e começa a ficção? Poderemos considerar o jornalismo um medium literário? Como defender a utilização de técnicas, no fundo importadas da narrativa ficcional oitocentista, para construir histórias credíveis e que mantenham o pacto de verdade com os leitores? Na verdade, as técnicas ficcionais do Novo Jornalismo derivam da combinação do jornalismo periódico e da arte de contar histórias que fez nascer o romance no século xviII.

Numa recente entrevista dada à Pública por Mark Kramer, conceituado professor e jornalista, o tema é recuperado. Segundo este autor, uma das formas 
de contornar a atual crise do jornalismo, nomeadamente do jornalismo escrito, será a recuperação destes princípios defendidos pelos repórteres norte-americanos da década de 60. Curiosamente, uma das motivações que explicam contextualmente o surgimento do Novo Jornalismo nos Estados Unidos são de índole comercial e económica. Na verdade, como explica John Hollowell, nos finais dos anos 50, os custos de produção e a baixa das receitas publicitárias devida à era dos media eletrónicos, como a televisão, obrigaram muitas publicações a encerrar a sua atividade. Assim, uma das saídas para esta crise foi lançar no mercado novas experiências, das quais a "não ficção" foi a mais importante, tornando o jornal e a reportagem mais apelativos para os leitores.

Regressando a Mark Kramer, o modelo defendido por este autor é o de um jornalismo narrativo:

"A minha análise da utilidade da narrativa sugere que, mostrando a complexidade das histórias que são notícia e a real situação humana dos seus intervenientes, situações que os leitores podem compreender facilmente, os jornais podem revitalizar-se e tornar-se mais interessantes" (Kramer, 2010).

Alertado para a perigosa e indesejável contaminação do jornalismo pela literatura, Kramer privilegia o termo jornalismo narrativo em detrimento do de jornalismo literário. No fundo, aquilo que é defendido é a reutilização do potencial narrativo dos textos, a exploração de diversas ferramentas narrativas, a fim de restituir aos jornais a sua função primordial: contar histórias, com densidade, que impliquem o envolvimento do leitor, que problematizem o real, traduzindo-o em toda a sua complexidade.

Se pensarmos que toda a prática jornalística passa precisamente por esta capacidade de narrativizar o real, facilmente perceberemos que todo o jornalismo é narrativo, pois todo ele pressupõe a seleção de histórias e a organização discursiva de factos. Ao fazê-lo, qualquer jornalista se desdobra numa voz, submetendo-se a convenções editoriais que lhe ditam as regras de construção e composição de uma história. Aquilo que jornalistas como Mailer, Capote ou Wolfe fizeram foi lutar contra essa tendência de uniformização, defendendo e impondo as suas visões pessoais, as suas sensibilidades e as suas cosmovisões. 


\section{Narrativa e objetividade}

É chegado o momento de uma sistematização prévia. Acabámos de citar duas opiniões sobre esta problemática. Ambas incidem sobre questões que consideramos cruciais nesta abordagem: em primeiro lugar, o facto de o jornalismo narrativo nos conduzir impreterivelmente a uma discussão em torno do conceito de narrativa ficcional; em segundo lugar, a revisão obrigatória do conceito de objetividade, neste contexto; em terceiro lugar, a necessidade imperiosa de se entender a narrativa como forma de acesso natural e intrínseca à condição humana.

Quando Juan Luís Cebrián, numa das suas cartas ao jovem Honório, começa o texto com "não deixes que a realidade te estrague uma boa reportagem" (Cebrián, 1998: 39), enceta, de modo provocatório, um interessante diálogo epistolar sobre a relação entre narrativa jornalística e narrativa literária. Essa relação é transversalmente atravessada por uma problemática, cuja complexidade não é compatível com o espaço de que aqui dispomos: trata-se da relação entre narrativas factuais e narrativas ficcionais. Embora não aprofundemos a questão, parece-nos incontornável explicitar alguns pressupostos de onde partimos.

A questão central pode sintetizar-se da seguinte forma: o que permite distinguir os Cem Anos de Solidão, enquanto exemplar ficcional, de Notícia de um Sequestro? Haverá algum sinal que indique ao leitor quando entramos no mundo possível da ficção? A verdade é que, do ponto de vista formal, os procedimentos textuais inerentes à ficção são os mesmos da narrativa factual. O que nos leva a ler como ficção a descrição do Chiado no final do romance queirosiano $O$ Crime do Padre Amaro? E porque lemos como verídica a História do Portugal Contemporâneo de Oliveira Martins?

Parece-nos, portanto, e seguindo a linha de raciocínio de Umberto Eco, que, do ponto de vista formal, não existe nenhum sinal ostensivo que assinale a narrativa de ficção, distinguindo-a da narrativa factual. Num texto já antigo, parece-nos que o semiótico italiano recoloca muito bem esta questão, defendendo o valor comunicacional das narrativas, cujo autor, título, medium, co-texto e enquadramento ensinariam o leitor a decodificá-las. Quer isto dizer que será no paratexto, enquanto lugar envolvente das narrativas, que se constroem os pactos de leitura que orientarão o horizonte de expectativas do leitor na sua 
decodificação (Eco, 1997). Neste sentido, deveremos perspetivar a ficcionalidade, como modalidade literária, como um conjunto de regras de natureza comunicacional e não estilística, como bem o demonstrou Maria Augusta Babo:

"Do ponto de vista da estrutura narrativa não nos é possível encontrar uma diversidade estruturante entre as chamadas narrativas ficcionais e as ditas narrativas factuais. Quer dizer que os procedimentos textuais inerentes à ficção, na literatura, são os mesmos, do ponto de vista formal, da narrativa histórica ou jornalística. O que se passa é que a condição da própria "mise-en-intrigue"ou narratividade é a da produção, configuração do sentido, independentemente da referência. E essa configuração passa, no entender por exemplo de um Ricoeur, pela organização interna da temporalidade, organização essa que é talvez, para este autor, mais rica de potencialidades na ficção do que na narrativa factual; a diferença não constituindo sequer uma mudança de género mas um grau maior de capacidade a refigurar o tempo e a referencialidade." (Babo, 1996: 3).

Segundo Searl, a ficcionalidade não reside numa qualquer especificidade estilística ou numa qualquer função metafórica da linguagem, mas sim numa intenção de comunicação que é da inteira responsabilidade do autor. Assim sendo, a ficcionalidade é um valor ilocutório do enunciado que se prende com o fingimento intencional do autor, por um lado, e, por outro, está suportada por um conjunto de convenções comunicacionais que a distinguem da mentira e, finalmente, depende do pacto estabelecido com o leitor. No fundo, a questão reside naquilo a que Umberto Eco chama de "protocolos ficcionais", que mais não são do que pactos de leitura previamente estabelecidos entre autor e leitor, geralmente inscritos na zona paratextual (Eco, 1997). Para o que nos interessa discutir aqui, é importante perceber que o jornal é portador implícito de narrativas naturais / factuais, pois o leitor espera encontrar nele histórias reais e não efabulações possíveis. O pacto que o jornalismo estabelece com os leitores é o pacto de verdade e de honestidade: o público lê estas narrativas como índices de real. Mais uma vez é uma questão pragmática que se prende, por um lado, com o protocolo de leitura e, por outro, com uma questão ética e deontológica de honestidade. 
Passemos agora ao segundo ponto atrás enunciado: a questão, igualmente complexa e muito ligada a esta última, da objetividade jornalística. Para Jay Rosen, os critérios de objetividade jornalística têm a ver também com um pacto comunicacional - implícito - entre jornalistas e empresários, assinado no início da industrialização da imprensa. A comercialização de que nos fala Rosen traduz-se, no plano narrativo, numa linguagem cada vez mais sintética, em textos cada vez mais curtos, na uniformização dos temas abordados, etc. Enfim, num jornalismo muito mais pobre em termos de conteúdo, construído por narrativas formatadas, pretensamente objetivas, mas não raras vezes mais subjetivas do que se fossem objeto de trabalho mais apurado. Partindo da análise de um conjunto de narrativas mediáticas portuguesas sobre acontecimentos relativamente recentes, Mário Mesquita ecoa esta opinião, ao aceitar a posição de Deni Elliot, segundo a qual a crise do jornalismo advém de um choque de modelos, entre os "rituais da objetividade" e a vertiginosa velocidade da circulação da informação (Mesquita, 2003).

As narrativas jornalísticas são também construções e representações da realidade que relevam de escolhas ideacionais e interpessoais, para utilizarmos os termos da gramática de Halliday. As notícias não são listas de eventos, nem são factos, muito menos a realidade. As notícias são representações em linguagem verbal e/ou não verbal: representações discursivas e sociais, construções textuais que implicam a intervenção de um conjunto lato de signos e de códigos, que modelam e constroem a nossa perceção da realidade (Tuchman, 2002).

Assim, uma análise semiótica dos jornais deverá considerar que tipo de mensagens são comunicadas pelos códigos do discurso das notícias, os contextos em que essas notícias são produzidas pelos jornalistas e descodificadas pelos leitores, bem como o significado ideológico do discurso noticioso. Ora, um jornal incorpora códigos muito específicos bem como outros usados noutras áreas e produtos sociais, sendo a narrativa um deles (Bignell, 2002: 81-108).

A notícia não é uma categoria fixa que exista naturalmente, resultando antes de um modo de pensar, de selecionar e de compor segundo códigos retóricos, éticos e deontológicos. Assenta numa seleção de factos, assumidos como significativos segundo critérios de seleção específicos, os chamados valores-notícia, partilhados por um corpo profissional e que, afinal, são os responsáveis pela estruturação dos acontecimentos em narrativas de informação. 
Se pensarmos na estrutura narrativa da notícia, tal como foi cristalizada no final do século xix, na era da massificação do jornalismo, perceberemos que nada há de natural na existência de um lead, nem no conjunto de fatores que obrigatoriamente o integram. Esta constatação tem sido estudada pelos historiadores dos media que têm demonstrado que, à época, um conjunto de fatores económicos, políticos e até tecnológicos conduziram o jornalismo norte-americano a ditar uma estrutura tida como eficiente que se coadunava não apenas com a objetividade almejada mas também com a relação comunicacional entre jornais e públicos ${ }^{121}$.

A objetividade é, portanto, um significado mítico do discurso noticioso criado por assunções sobre notícias e sobre a profissão. Se partirmos do pressuposto de que qualquer enunciado em linguagem verbal é produto de uma subjetividade, perceberemos que o texto jornalístico pode ter a objetividade como meta, como baliza, mas nunca a poderá concretizar plenamente. No entanto, citando uma vez mais Mário Mesquita, também é em nome da objetividade e da independência que se insinua o poder do jornalismo. Deste modo, entendemos que o autor recoloca muito bem a questão, entendendo a objetividade como escopo situado a tês níveis distintos: no plano deontológico, como um dever; no plano retórico, como um conjunto de regras estilísticas; no plano de investigação jornalística como um leque de normas processuais (Mesquita, 2003: 207-217).

À semelhança do que constatámos relativamente à ficcionalidade, também a objetividade jornalística deve ser integrada no pacto comunicacional com o leitor, que espera das narrativas textos factuais, honestos, imparciais e objetivos.

A etimologia das palavras narrativa e narração ${ }^{122}$ evidencia a íntima conexão existente entre narrativa e conhecimento. Não é por acaso que desde a nossa infância, as histórias são a principal fonte de conhecimento sobre o mundo e um importante meio de dar sentido à experiência. A narrativa está, portanto,

121 No artigo de Mário Mesquita «Em louvor da Santa Objetividade», são circunstanciadamente explicados os fatores históricos que concorreram para a criação da objetividade, então intimamente ligada a estruturas textuais. É sobretudo a partir do século xix que o conceito de objetividade adquire pertinência no caso do jornalismo, na fase industrial da imprensa: grande público; massificação; credenciação dos jornais; profissionalização dos jornalistas; emergência das agências noticiosas; estratégia comercial. No início do século xx, o conceito impõe-se nos EUA: evitar o sensacionalismo; distinguir-se das Relações Públicas (Mesquita, 2003).

122 Os termos narrativa, narração e narrar derivam do Latim: narrare, narratum e narro, que por sua vez advêm do adjetivo gnarus, que significava sabedor, aquele que conhece. 
presente em todos os lugares e em todas as sociedades: a nossa tendência para organizar a experiência em forma narrativa é um impulso humano sincrónico com a aquisição da linguagem. Temos, pois, uma predisposição primitiva e inata para a organização narrativa da realidade. Inclusive, alguns autores acreditam que já nascemos com um sentido intuitivo e natural para a narrativa e que contar e perceber as nossas vidas como narrativas é algo de comum a todos os grupos e sociedades. Foi esta a tese de Roland Barthes quando, no célebre número 8 da revista Communications, defendeu a transculturalidade da narrativa: as narrativas são um fenómeno universal e até podem evidenciar estruturas universais, defendendo que o estudo das narrativas deve ser um dos mais importantes inquéritos da atividade humana (Barthes, 1968: 1-3).

Uma narrativa é simultaneamente "um modo particular de combinar as partes num todo", um processo dinâmico de comunicação, uma construção de sentido e uma representação social. Partindo destes pressupostos, aceita-se, então, como válida a definição de Labov que define a narrativa como "um método de recapitulação da experiência passada que consiste em fazer corresponder uma sequência de eventos a uma sequência de proposições verbais." (Labov, 1978). Podemos, então, entender a narrativa como o resultado da discursivização da experiência humana: trata-se, no fundo, de construir um processo de representação dinâmica de factos, acontecimentos, passados num tempo específico.

Por isso, perspetivar o jornalismo sob o prisma narratológico também é importante porque nos ajuda a perceber como o conhecimento, os sentidos, os valores são reproduzidos e circulam na sociedade. Porém, as narrativas mediáticas não refletem apenas o mundo real: elas providenciam esquemas mentais e formas de moldar os nossos modos de percecionar, conhecer e acreditar.

Por tudo o que foi dito até ao momento, aceita-se com Carlos Reis que o processo narrativo possa ser descrito em três vertentes: ele decorre de uma atitude de distanciamento assumida por quem narra em relação ao que narra; resulta de uma tendência para a exteriorização, já que descreve e caracteriza um universo autónomo, exterior ao sujeito que o desencadeia; e instaura uma dinâmica temporal que se alimenta não só do devir cronológico da história contada mas também da temporalidade inerente ao próprio discurso (Reis, 1995).

São precisamente estes vetores que, em nosso entender, justificam que a narratividade se revele como o modo fundacional do discurso jornalístico. Mas 
ao fazê-lo, devemos admitir que contar histórias envolve sempre uma atividade de seleção e omissão do material narrável, sendo que o que se omite é por vezes tão importante quanto o que se seleciona. Torna-se, assim, claro que uma narrativa não é uma amálgama de eventos. Quando contamos uma história, tentamos dar sentido a conexões causais entre eventos e ações, também nos preocupamos em situar os eventos no tempo e no espaço, organizando-os numa determinada ordem. O que é caótico, simultâneo, desordenado passa a ter um significado e uma organização.

Esta é, de facto, a tarefa do jornalismo: olhar a realidade, multimodal, desordenada, multifacetada e transformá-la em acontecimento legível. Esta tarefa, que no fundo é a tarefa de qualquer narrador em qualquer situação, envolve uma triagem, uma hierarquização. Envolve escolhas, sempre filtradas por uma subjetividade. Envolve o domínio de um conjunto de códigos que regulam o funcionamento das narrativas, independentemente da sua forma de expressão.

Como afirma Helen Fulton, num mundo dominado por media impressos e eletrónicos, é crucial que percebamos como funcionam as narrativas por eles estruturadas, como explicam as causas e os efeitos dos eventos e das ações, pois esse é um passo imprescindível para que consigamos entender como os media constroem o nosso conhecimento do mundo social e político. As narrativas dos media, tal como as outras, são contadas a partir de perspetivas específicas, privilegiando certos pontos de vista e certas versões, em detrimento de outras, construindo personagens, dando voz a determinados atores sociais e silenciando outros. Saber o que as histórias mediáticas nos contam e aquilo que escondem ou omitem é crucial para entender o exercício de poder em sociedade e para perceber que sentidos são produzidos (Fulton, 2005).

Assim, os Estudos Narrativos defendem a existência de aspetos comuns a todas as narrativas, sejam elas de índole literária, histórica, cinematográfica, televisiva ou jornalística. Estes fatores apontam para a possibilidade de se estudar a narratividade como processo geral que é comum a todas as narrativas. Não cabendo aqui o desenvolvimento do conceito de narratividade, gostaríamos de adotar a perspetiva de Gerald Prince que prevê que a narratividade não pode circunscrever-se a particularidades intrínsecas ao texto, antes deve ser entendida numa aceção pragmática, em que o leitor assume um papel preponderante. Ou seja, para além da dinâmica de transformação desencadeada pelo texto narrativo, 
e salientada por autores como Greimas ou Ricoeur, a narratividade tem de ser considerada em estreita conexão com a instância da receção. Ela pode ser entendida, segundo os autores do Dicionário de Narratologia, como uma qualidade discursiva que é atualizada pelo processo de leitura, ou seja, é um processo inerente à dinâmica de transformação desencadeada pelo texto narrativo, mas é também uma referência latente que organiza a descodificação da narrativa (Reis e Lopes, 1994: 274-285).

Trata-se, portanto, de entender a narratividade neste duplo enquadramento, conjugando a sua vertente de condição específica do texto narrativo, constituída essencialmente pela dinâmica temporal que preside à sua constituição e, por outro lado, como conjunto de características que condicionam e orientam as expectativas de leitura.

Assim sendo, o facto de defendermos para o jornalismo uma linha narrativa não implica necessariamente que entendamos que o princípio da objetividade, entendido como um pacto comunicacional com os leitores, deva ser posto em questão. Nem tão pouco aceitaremos que se confunda o cariz narrativo do jornalismo com a vertente de entretenimento também presente em muitas narrativas mediáticas, nomeadamente nas televisivas. Acreditamos que, ao construir narrativas sobre o mundo, ao tornar legível e ao dar sentido à realidade, o jornalista deve explorar as potencialidades que a narrativa possui, de forma a abarcar a complexidade do real. Ora, tal investimento não é compaginável com a submissão do jornalismo a lógicas de competitividade capitalistas, promotoras de uma simplificação e de um empobrecimento de conteúdos, por um lado, e por outro responsáveis pela manipulação das narrativas, no sentido de as transformar em elementos tão persuasores quanto a publicidade.

\section{Em síntese: jornalismo narrativo}

Partindo desta abordagem pragmática da narratividade, em que ao leitor cabe o papel ativo de refiguração e reconstrução do mundo do texto narrativo, parece-nos fazer todo o sentido defender que, em termos contextuais, o jornalismo escrito pode, de facto, revitalizar-se se enveredar em parte pela aposta noutros tipos de narrativa. 
Esta hipótese pressupõe naturalmente um conjunto de mudanças estruturais, quer na constituição do próprio jornal, quer na mentalidade de editores e diretores. Não se trata, naturalmente, de transformar o jornal num objeto de culto de estrelas escritoras, nem tão-pouco de o remeter para pequenas elites intelectuais. Pelo contrário. Acreditamos poder ser possível enriquecer as páginas dos jornais com novas narrativas, que coexistam com a tradicional forma de fazer jornalismo: apostar nas grandes reportagens, nos perfis, nos artigos de fundo.

Esta mudança, que paulatinamente já começou em algumas redações norte-americanas e brasileiras, em que existem "equipas narrativas" para cobrir esta área, implicará alterações substanciais não apenas na relação do repórter com as pessoas, com as fontes e com os eventos que descreve, mas também e sobretudo na arquitetura e no estilo das histórias contadas que passarão a enriquecer-se com estratégias tradicionalmente ligadas à ficção, sobretudo ao romance e às histórias breves. No fundo, não se trata de abandonar a objetividade mas de a perspetivar de uma forma muito mais profunda: deve ser-se sério e honesto, revelando opiniões pessoais, admitindo preconceitos e valores. Usando técnicas literárias, o jornalismo narrativo constrói informação, conferindo espessura às suas histórias, nem sempre possíveis de obter num jornal ou numa revista noticiosa, e permitindo ao leitor imergir na história de um modo muito mais denso, profundo e completo. Atente-se nas palavras de Gay Talese na célebre obra Fame and Obscurity:

\footnotetext{
"O melhor novo jornalismo, apesar de lido muitas vezes como ficção, não é ficção. É, ou deveria ser, tão real como qualquer outra reportagem, oferecendo uma verdade tão profunda quanto possível através da compilação de factos verificáveis. (...) Mas exige uma abordagem mais imaginativa no ato de reportar."
}

Desta forma, creio que os jornais recuperariam um espaço há muito perdido, em que a imaginação, a poética, a arte de bem escrever responderiam a uma das necessidades dos leitores: sentir prazer na leitura. Na Poética de Aristóteles, o filósofo argumenta que as histórias dão prazer porque imitam a vida e possuem um ritmo próprio, com certas ações e mudanças. De facto, para explicarmos a nossa apetência por histórias, temos de perceber que elas mostram e contam 
os desejos das personagens mas também os das audiências, convidando à identificação e incentivando ao prazer de saber e de descobrir.

Não se trata aqui, sublinhe-se, de fazer a apologia de um jornalismo fundado no conceito de entretenimento ou de ficção. Trata-se, antes, de fazer o elogio do prazer do texto, para roubar um brilhante conceito barthesiano. No fundo, o ideal seria, agora citando Mário Mesquita, fundir a "orientação apolínea" da prática jornalística, que defende o prosaísmo e a objetividade, com a "tendência dionisíaca”, tendencialmente poética e subjetiva (Mesquita, 2004: 56). Cremos que tal sintonia, embora difícil, não é de todo impossível. A nossa história da imprensa recente conta com nomes que foram a prova viva desse enlace.

\section{BIBLIOGRAFIA}

Babo, M. A. (1996). Ficcionalidade e processos comunicacionais. In: www.bocc.ubi.pt

Barthes, R. (1968). "Analyse Structurale du Récit». In: Communications, 8, pp. 1-27.

Bignell, J., (2002), "Newspapers», Media Semiotics An Introduction. Manchester University Press, pp. 81-108.

Bremond, C. (1973). Logique du Récit. Paris: Seuil.

Ceia, C. (2011). "Estranhamento", E-Dicionário de Termos Literários. coord. de Carlos Ceia, ISBN: 989-20-0088-9, <http://www.edtl.com.pt>, consultado em 1/05/2011.

Charron, J. e Bonville, J., (2004). "Le Journalisme et le marché: de la concurrence à l'hiperconcurrence». In: Brin, C. et alii, Nature et Transformation du Journalisme - Théories et Recherches empiriques. Laval: Les Presses Universitaires de Laval, pp. 292-293.

Correia, N. (2010). "L'Europe des Médias face à la crise». In: Les Cahiers du Journalisme, n. 21 - Automne, pp. 298-318.

Delporte, C., (1995). Histoire du Journalisme et des Journalistes en France (du XvII siècle à nos jours). Paris: P. U.F., Col. "Que sais-je?».

Eco, U., (1997). Seis Passeios nos Bosques da Ficção. Carnaxide: Difel.

Ferenczi, T., (1993). Linvention du journalisme en France. Naissance de la presse moderne à la fin du XIX siècle. Paris: Plon.

Fulton, H. et alii, (2005). Narrative and Media. Cambridge, New York: Cambridge University Press.

Hellmann, J., (1981). Fables of fact: the new journalism as new fiction. Chicago, London. The University of Illinois Press. 
Herman, D. ; Jahn, M. ; Ryan, M.-L. (eds.) (2005). The Routledge Encyclopedia of Narrative Theory. London: Routledge.

Hollowell, J., (1977). New journalism and the nonfiction novel. Chapel Hill: The University of North Carolina Press.

Iser, W., (1979). «La fiction en effet», Poétique, no 39, septembre, pp. 275-298.

Keeble, R. and Wheeler, S. (eds.) (2007). The Journalistic Imagination. Literary Journalists from Defoe to Capote and Carter. London e New York: Routledge.

Kramer, M. (2010). «Entrevista» a Paulo Madeira in: Pública.

Labov, W. (1978). "La transformation du vécu à travers la syntaxe narrative". In: Le parler ordinaire. Paris: Ed. Minuit.

Lotman, I. (1973). La Structure du Texte Artistique. Paris: Gallimard.

Mesquita, M. (2003). "Rumos do Jornalismo na Era da Hipérbole». O Quarto Equívoco. Coimbra: Minerva, pp. 53-58.

Mesquita, M., (2000). «Em louvor da santa objectividade», JJ, Janeiro-Março, pp. 22-27.

Pinto, M., (2008). «Digressão sobre a 'crise do jornalismo' - entre definhamento e re-invenção». Texto da lição de síntese apresentada como requisito das Provas de Agregação no ramo de Ciências da Comunicação, Universidade do Minho. In: http://novosmedia.org (consultado em 20/02/11).

Reis, C. e Lopes, A. C., (1994). Dicionário de Narratologia. 4ed., Coimbra: Almedina.

Reis, C. (1995). O Conhecimento da Literatura. 1ªed., Coimbra: Almedina.

Tuchman, G., (2002). "As notícias como uma realidade construída». In: Media e Jornalismo. Lisboa: CIMJ, pp. 91- 102.

Wolfe, T., (1990). The new journalism. London: Picador / Id., (1992), El nuevo periodismo, $5^{\mathrm{a}} \mathrm{ed}$. Barcelona: Anagrama. 